\title{
Hyaluronic acid for lower eyelid and tear trough rejuvenation: review of the literature
}

\author{
Alberto Diaspro', Giuseppe Sito² \\ 'Department of Maxillofacial and Facial Plastic Surgery, Rigeneralab Centre for Regenerative Medicine, Turin 10134, Italy. \\ ${ }^{2}$ Department of Aesthetic Surgery and Medicine, Pegaso University, Naples 80121, Italy.
}

Correspondence to: Dr. Alberto Diaspro, Department of Maxillofacial and Facial Plastic Surgery, Rigeneralab Centre for Regenerative Medicine, Corso Unione Sovietica 159/a, Turin 10134, Italy. E-mail: info@albertodiaspro.com

How to cite this article: Diaspro A, Sito G. Hyaluronic acid for lower eyelid and tear trough rejuvenation: review of the literature. Plast Aesthet Res 2020;7:62. http://dx.doi.org/10.20517/2347-9264.2020.143

Received: 30 Jun 2020 First Decision: 10 Aug 2020 Revised: 23 Aug 2020 Accepted: 23 Sep 2020 Published: 6 Nov 2020

Academic Editor: Wen-Guo Cui Copy Editor: Cai-Hong Wang Production Editor: Jing Yu

\begin{abstract}
Periorbital aging has been identified as one of the most important aesthetic concerns of the face, so that lower eyelid rejuvenation has become a topic of major interest. Not every patient requires surgical blepharoplasty and selected lower eyelid problems and defects due to the aging process have been treated with hyaluronic acid (HA) gel injections since 2004. With this as the premise, the current work serves to review the published medical literature on the use of $\mathrm{HA}$ for lower eyelid and tear trough rejuvenation. A PubMed search was carried out in May 2020 using the search terms: "Tear trough [and] HA [and] filler"; "Tear trough [and] HA"; "HA [and] lower eyelid [and] filler"; "HA [and] lower eyelid". A large number of relevant studies were identified. Surgical management remains the gold standard for lower eyelid rejuvenation but increasingly, non-surgical correction of selected deformities with HA injection may provide a reliable option based on the available evidence. Further, prospective randomized controlled studies and systematic reviews of the literature are nevertheless desirable and a standardized, widely accepted grading system of the deformity and its treatment outcomes will allow us to codify this procedure better.
\end{abstract}

Keywords: Eyelid, tear trough, hyaluronic acid, rejuvenation

\section{INTRODUCTION}

The eyes are located in the centre of the face and are crucial to its aesthetic appeal. It is therefore of major concern to patients. Because minor changes to the eyes can yield dramatic results, many aesthetic

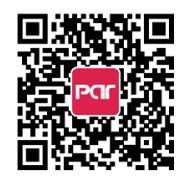


procedures have been described, such as brow lifting, autologous fat transfer, surgical excision, chemical peels and lasers.

The nasojugal fold was first described by Loeb ${ }^{[1]}$ in 1981. It is the groove resulting from attachment of the lower dermis to the periosteum of the infraorbital margin, which accentuates the depression of the eyelids against the heavier bulk of tissue towards the nasal wall.

However, Flowers ${ }^{[2]}$ in 1993 reported and named the "tear trough deformity" with reference to its correction by techniques utilizing alloplastic implants.

The treatment options to correct a hollow, lower lid area have since been further developed: Hamra et al. ${ }^{[3]}$ for instance, filled the trough by means of vascularised fat transposed through release of the arcus marginalis. Other surgical techniques to addressorbital fat reposition have also been published ${ }^{[4,5]}$ and fat injections have been proposed as a non-vascularised graft to fill the tear trough ${ }^{[6,7]}$.

The aforementioned techniques represent different degrees of invasiveness while non-surgical options allow treatment of dark pigmentation but do not successfully treat sunken lower eyelids ${ }^{[8,9]}$.

Proper understanding of the role of the orbitomalar ligament in tear trough deformities, as well as of progressively worsening midface ptosis ${ }^{[10]}$, has subsequently enabled the opportunity to inject filling agents other than fat to fill the hollow and in so doing, rejuvenate the lower eyelid area, in order to obtain the same outcome without the downtime from surgery.

Hyaluronic acid (HA) gel injections were first used for this purpose in $2005^{[1,12]}$ and since then, this nonsurgical, outpatient procedure has been one of the mainstays of HA filler treatment.

As long as the non-surgical procedure does not violate the key anatomical structures and relationships of the lower eyelid, it can be adopted in properly selected patients as a simple method to accomplish its rejuvenation. Not every patient requires a surgical blepharoplasty to meet their needs and selected lower eyelid deformities and defects due to aging can still be treated easily, safely, and quickly with HA injections.

This study has thus been carried out to review the published medical literature on the use of HA for lower eyelid and tear trough rejuvenation.

\section{DATA COLLECTION}

A PubMed search was performed in May 2020 using the strings: "Tear trough [and] HA [and] filler"; "Tear trough [and] HA"; "HA [and] lower eyelid [and] filler"; "HA [and] lower eyelid", which yielded a total of 242 indexed articles.

Results were limited to human subjects, in clinical trials, randomized controlled trials, case reports, comparative studies, controlled clinical trials and multi-center studies.

No limits based on the year or language of publication was applied.

Manual review of abstracts was also performed to omit unrelated articles.

The final result included 66 articles from 2005 to 2020. 
50

37,5

Z 25

12,5

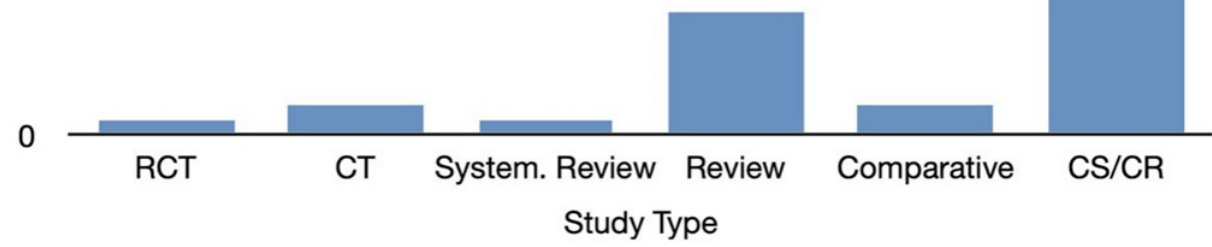

Figure 1. Retrieved articles: study type. RCT: Randomized Controlled Trial; CT: Controlled Trial; System. Review: Systematic Review; Comparative: Comparative Study; CS: Case Serie; CR: Case Report

\section{DATA DISTRIBUTION}

\section{Study type}

There were eighteen prospective studies ${ }^{[12-21]}$, twenty retrospective studies ${ }^{[22-31]}$, and one that was both retrospective and prospective ${ }^{[32]}$; the study type was not mentioned in twenty-seven ${ }^{[33-42]}$.

Among the published papers, there has only been one randomized controlled study ${ }^{[43]}$ on HA injections performed to rejuvenate the tear trough area, along with two controlled trials ${ }^{[16,40]}$.

A systematic review presented with a meta-analysis ${ }^{[4]}$ has been carried out in order to evaluate treatment for cicatricial ectropion including HA injection among non-surgical treatments.

Eight review articles have been written, the first in $2007^{[33]}$, then in $2010^{[36]}, 2012^{[38-40]}$ and from 2016 to $2020^{[44-47]}$, and two comparative studies were published in $2006^{[13,22]}$.

Twenty-nine papers are case-series ${ }^{[1,18,27-29,48-52]}$, thirteen are case-reports ${ }^{[20,30,31,37,39,53-57]}$ whilst the remainder ${ }^{[26,34,35,40,58-66]}$ are related to general content [Figure 1].

\section{Follow-up duration}

The mean recorded follow-up was 18.2 months $s^{[11-34]}$, ranging from 0.75 (3 weeks $)^{[17,27,66]}$ to 96 months (8 years) ${ }^{[24]}$.

\section{Average study population}

The study of Airan and Born ${ }^{[11]}$ remains the largest, with 400 treated patients, followed by the paper edited by Artzi et al. ${ }^{[51]}$, which reviewed 351 patients.

Among the investigated articles which directly mentioned the study population ${ }^{[14-16,21,26,32,34,63,66-68]}$, the average (n) was 71.37, and ranged from $3^{[18]}$ to $400^{[11]}$ once case reports were excluded. 


\section{Anatomy}

Since 2012, three papers have been published with regard to anatomical topics: interestingly, those published in $2012^{[58]}$ and $2013^{[60]}$ were both focused on the tear trough region, whilst that in $2015^{[61]}$ was targeted at anatomical knowledge applied to the midface and not only the lower eyelid.

\section{Classification}

Two articles provided a classification system for tear trough deformities, along with a review of the available treatments ${ }^{[45]}$, and presented a series of treated patients in order to establish correlation with achieved outcomes $^{[62]}$.

\section{Complications}

Complication-related papers have been published since $2012^{[25,39]}$, and have been reported consistently in $2014^{[68]}, 2016^{[51,69]}, 2017^{[29,53,54]}, 2018^{[69]}, 2019^{[20,55-57,63]}$ and $2020^{[70]}$. These are either case reports or case series, and one did not mention the size of the study population. The reported follow-up duration, when mentioned, ranged from 12 months ${ }^{[29]}$ to 5 years ${ }^{[39,69]}$, with prolonged edema, the Tyndall effect and contour irregularities as the most commonly reported complications, along with diplopia ${ }^{[25]}$, and xanthelasma-like reactions ${ }^{[53]}$ as a rare occurrence. Complications were also reported in several articles, even if not the focus of the study ${ }^{[13,17,22,28,32,71-75]}$, and included two cases of cellulitis and one of migraine ${ }^{[13]}$.

\section{Technique}

Research focused on personal techniques purposed by the authors have been published since 2005. Airan and Born ${ }^{[11]}$ and Kane ${ }^{[12]}$ wrote the first articles ever about this topic, both in 2005; technique refinement and new trends have been published in $2006^{[22,23]}, 2007^{[24,33]}, 2011^{[16,32,76]}, 2012^{[26,41,42,66]}, 2013^{[73]}, 2014^{[43]}$, $2015^{[48-50]}, 2016^{[27,28]}, 2017^{[17,52]}, 2018^{[19,71,74]}$ and $2019^{[21]}$.

Anaesthesia has been used both by local infiltration ${ }^{[11,19,24,31]}$ or by topical application ${ }^{[13-17,48,52]}$.

Injections performed by needle have been described since 2005 up to $2019^{[11-16,21,28,33,74]}$, while cannula use has been reported since $2017^{[19,30,31,52,71]}$ and only two studies reported both techniques ${ }^{[17,62]}$.

The injection depth is reported to be carried out directly at the orbital bony border ${ }^{[11,13,15,16,19,27,48,71,73,74]}$, either under the orbicularis oculi muscle $e^{[14,24,31,32,50,66,71,74]}$ or subcutaneously ${ }^{[12,33]}$. The average amount of HA injected into each side is $0.56 \mathrm{~mL}$ and ranges from $0.2 \mathrm{~mL}^{[12]}$ to $2.0 \mathrm{~mL}^{[44]}$.

\section{Endpoint}

Of the 66 studies included for analysis, the majority ${ }^{[19,24,30,31,33,36,62,69,71,74]}$ were focused on tear trough rejuvenation whilst 10 reported HA injections to treat functional impairments such as lower eyelid $\operatorname{retraction}^{[23,35,37,67]}$, cicatricial $^{[34,41,75]}$ and involutive ectropion ${ }^{[18]}$, and suprachoroidal buckling ${ }^{[40,58]}$.

\section{Outcome evaluation}

In 2010, two papers on objective and validated measurements of the achievable results of non-surgical tear trough rejuvenation as assessed by digital $3 \mathrm{D}$ photographs and cutometer were published ${ }^{[14-16,76]}$. The papers had not been presented up to $2018^{[7]}$ and this topic has not been further investigated.

\section{DATA REVISION}

This review of the medical literature on HA use for lower eyelid and tear trough rejuvenation identified a large number of related studies. 


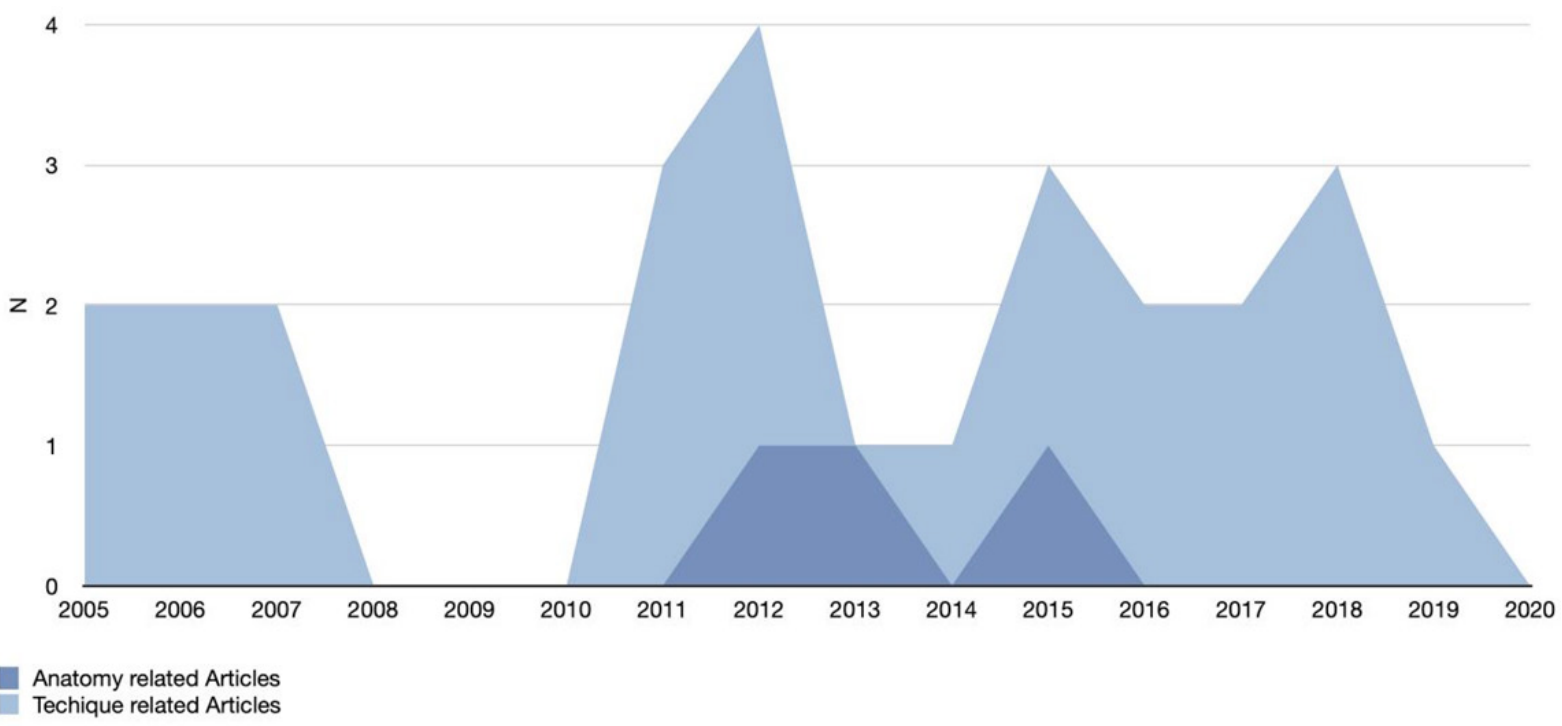

Figure 2. Anatomy and technical note focused articles: publication trend

The average study population was 71.37 , ranging from $3^{[44]}$ to $400^{[11]}$ treated patients, along with a recorded mean follow-up of 18.2 months, ranging from 0.75 ( 3 weeks) ${ }^{[17,27,66]}$ to 96 months ( 8 years ${ }^{[24]}$.

It is remarkable that the first two papers ever published on the topic already had 6.5 months of retrospective follow-up of 400 treated patients ${ }^{[11]}$, and 9 months of prospective follow-up of treated patients ${ }^{[12]}$.

Even though the lower eyelid and tear trough are considered difficult sites to be injected, only two papers focused on related anatomy were published in $2012^{[58,60]}$, seven years after the technique was introduced ${ }^{[11,12]}$. Subsequently, the anatomy and the aging process of the tear trough region have started to be considered as strongly correlated to the midface ${ }^{[6]]}$ and thus, were no longer published as stand-alone topics [Figure 2].

The first papers focused on complications arising from lower eyelid and tear trough HA treatment were published in 2012 by Dayan et al. ${ }^{[39]}$ and Kashkouli et al. ${ }^{[25]}$.

Articles focused on complications have since been constantly published ${ }^{[20,51,53-57,63,68,69]}$, up to $2020^{[70]}$, which highlights the technical complexities of this treatment that requires adequate skills for it to be properly performed [Figure 3].

However, adverse events are occasionally reported in articles that are not directly related ${ }^{[13,17,22,28,32,39,71]}$.

The most commonly reported complications include the Tyndall effect ${ }^{[51,63,69]}$, a blue-grey dyschromia, in up to $30.5 \%$ of cases ${ }^{[69]}$; contour irregularities ${ }^{[25,51,53,63,69]}$ ranging from $4.25 \%{ }^{[51]}$ to $30.5 \%{ }^{[69]}$ of cases; and chronic malar oedema ${ }^{[2,54,63,68-70]}$ that has been reported in up to $11 \%$ of cases ${ }^{[69]}$.

Minor or rarely reported complications secondary to lower eyelid and tear trough HA injections are orbital cellulitis and migraine ${ }^{[13]}$, delayed resorption of $\mathrm{HA}^{[39]}$, diplopia ${ }^{[25]}$, xanthelasma-like eyelid skin reactions ${ }^{[29]}$, granuloma formation ${ }^{[55,56]}$ and lacrimal duct obstruction ${ }^{[57]}$ [Figure 4].

The injection of an adequate dose of hyaluronidase has always been reported to be the best treatment ${ }^{[54,57,63,68-70]}$, 


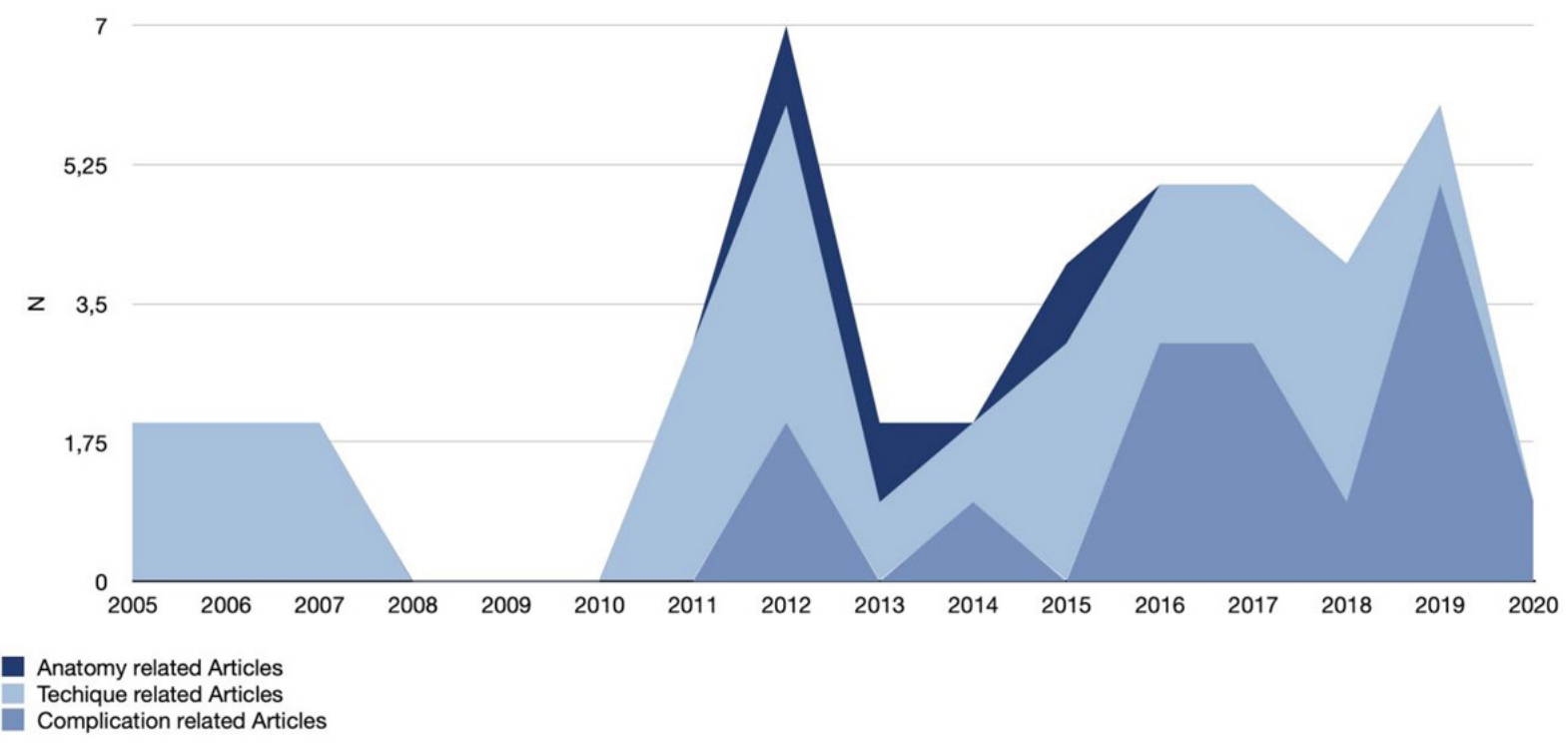

Figure 3. Complication focused articles: publication trend

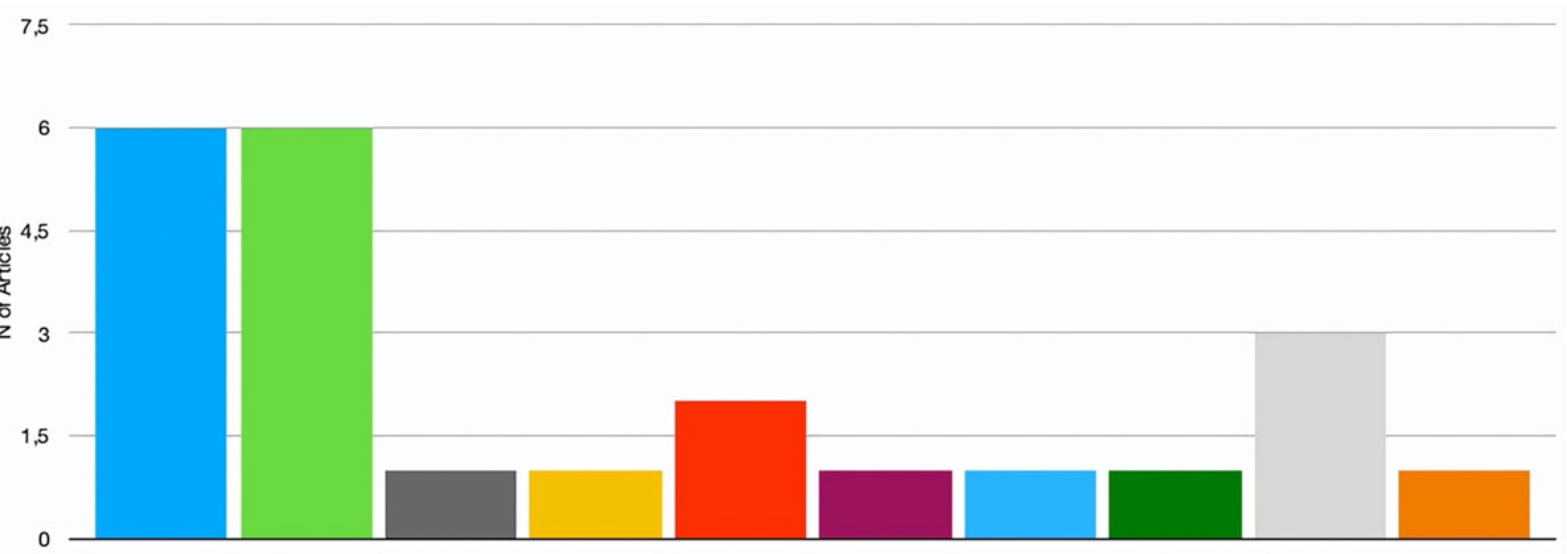

- Chronic Malar Oedema

Contour irregularities

- Delayed Resorption

$=$ Diplopia

- Granulama Rormation

- Lacrimal Duct Obstruction

Migraine

- Orbital Cellulitis

- Tyndall Effect (Blu-gray discoloration)

- Xanthelasma-like Skin Reaction

Figure 4. Reported complications

even if delayed with respect to primary onset, for these complications. Therefore, injecting with a reliable and safe technique plays a pivotal role in achieving optimal outcomes.

Indeed, publications on injection techniques constitute the majority ${ }^{[11-22,31,33,71]}$ of the recorded articles.

Local anaesthesia has been widely used, either topically ${ }^{[13-17,48,52]}$ or by local infiltration ${ }^{[11,16,60,61,66]}$. It has to be noted that care must be taken when injecting anaesthetic solution in order to avoid untoward alteration of the contours of the lower eyelid.

Nevertheless, some authors did not report the use of any form of anaesthesia for this treatment ${ }^{[32,73]}$. 
In order to avoid the complications above, it is mandatory to inject only a small quantity of HA, as the reported average amount has been $0.56 \mathrm{~mL}$, whilst ranging from $0.2 \mathrm{~mL}^{[12]}$ to $2.0 \mathrm{~mL}^{[48]}$ per side, in a deep plane on the inferior orbital rim, either pre-periosteal ${ }^{[11,13,15,16,19,27,48,71,73,74]}$ or under the orbicularis oculi muscle ${ }^{[14,24,31,32,50,52,66,71,74]}$.

Based on personal experience, the authors suggest injecting a lesser quantity of $0.2 \mathrm{~mL}$ to $0.45 \mathrm{~mL}$ per session $^{[77]}$, as the aforementioned $0.56 \mathrm{~mL}$ could include correction of both the tear trough deformity and the palpebro-malar groove ${ }^{[11,13,16,20,22,30-32,60,6]]}$.

The authors' preferred techniques are direct injection on the periosteum (GS) and retrograde injection technique deeper than the orbicularis muscle (AD).

The first requires the identification and protection of the infraorbital foramen with gentle finger pressure, followed by insertion of a 30-gauge needle into the deepest portion of the tear trough, which is always treated first by injection of the HA gel as a single bolus on the bony surface. The injected area is then gently massaged to create a natural shape and then assessed for further injections, if needed.

When a cannula is preferred, the entry point is located at the intersection between the vertical line passing through the external canthus and the line marked by the tear trough. Once inserted, it should pierce the orbicularis oculi muscle, and advanced until it reaches the bony orbital ridge. The infraorbital foramen will therefore be located deeper than the injection plane.

The cannula should then be moved medially toward the inner canthus and small amounts of HA are injected retrograde. Touch-up has been necessary within 1 month in around $20 \%$ of cases treated with cannula, normally requiring further injection of $0.1 \mathrm{~mL}$ to $0.3 \mathrm{~mL}$ of $\mathrm{HA}$ in order to improve the outcome of the previous session, whilst injections with needles did not require further corrections.

The choice between needle or cannula is based on personal experience and preference. While the authors experienced post-injection swelling and redness and pain in $2 \%$ to $3 \%$ of cases, less bruising and ecchymosis occur with the latter. Bruising may also cause lymphatic vessel compression with a greater risk of oedema, although it minimizes the risks of intravascular injection and embolism.

As a general rule, it is advisable not to inject medially in the inner canthus to avoid lesions or compression of the angular vessels ${ }^{[77]}$.

In the authors' experience, the use of cannula leads to overcorrection and the Tyndall effect in $6 \%$ to $7 \%$ of cases whilst needle injections avoid such complications; nevertheless, it has to be carried out by experienced injectors.

Subcutaneous placement of the HA is seldom reported ${ }^{[12,33]}$ and has not been mentioned since 2007 .

The injection can be performed by both the needle or cannula technique; it is remarkable that the technique with needle has been referred to since the very first papers in 2005 , up to $2019^{[11-16,21,24,33,74]}$, while the use of the cannula was not mentioned before $2017^{[19,30,31,52,71]}$.

The purpose of this paper is not to discuss the safety of these two methods of HA injection for tear trough and lower eyelid deformities, but it is the author's opinion that growing awareness of the relevant anatomy ${ }^{[58,60,61]}$ has supported the use of blunt cannulas as the safer choice for injectors, thus coinciding with the increasing rate of related papers after 2017 [Figure 5].

Finally, to highlight the reliability of HA injections for the treatment of lower eyelid deformities, 10 studies 


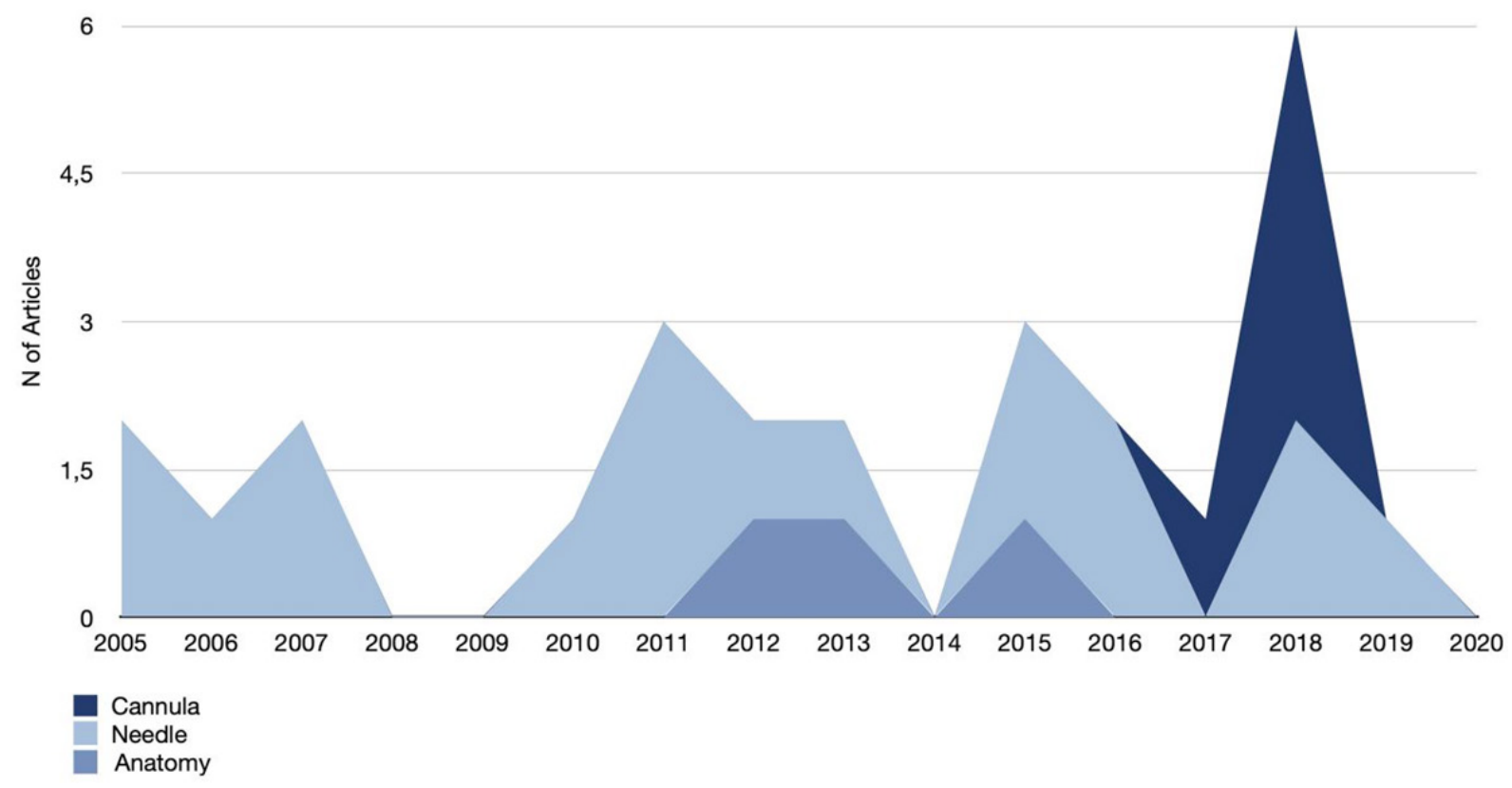

Figure 5. Complications focused articles: publication trend with respect to needle and cannula use

out of the 66 reviewed in this paper focused on its use in the treatment of functional impairments such as retraction $^{[23,35,37,67]}$, cicatricial ${ }^{[34,41,75]}$ and involutive ectropion ${ }^{[18]}$, and suprachoroidal buckling ${ }^{[40,59]}$, while the majority ${ }^{[11-13,19,22,30,62,69,71,74]}$ were, of course, focused on rejuvenation of the lower eyelid and tear trough.

With respect to the published literature, it could therefore be claimed that interest in lower eyelid and tear trough rejuvenation peaked in 2012, but has continued on an ascending trend, as summarized in Figure 6.

Indeed, this paper has some limitations as the presented review is non-systematic and therefore does not allow a meta-analysis of the collected data.

Furthermore, with respect to the Levels of Evidence classification of the Oxford Centre for Evidencebased Medicine $(\mathrm{OCEBM})^{[78]}$, the average level of evidence of the evaluated studies is low, as there was only one randomized controlled study ${ }^{[43]}$ on HA injections to rejuvenate the tear trough area (Level 1b), two controlled trials ${ }^{[16,41]}$ (Level 4), and a systematic review along with a meta-analysis ${ }^{[76]}$ (Level 3a), which has indeed been carried out in order to evaluate treatment of cicatricial ectropion and has been cited since it includes HA injections among non-surgical treatments.

The remaining literature was limited to case series, case reports and observational cohorts and lacks multicentre studies, highlighting the bias due to variances in single operator techniques.

Multiple classifications of the severity of tear trough deformities are presented ${ }^{[45,62]}$, although a standardized one is yet to be included in the current literature.

The lack of a grading system or classification directly correlates with the paucity of available articles focused on objective outcome evaluation of tear trough deformity treatment with HA injections. Digital 3D photography has been adopted as a method of choice since $2010^{[14,76]}$ but except for the paper published by Cho et al. ${ }^{[74]}$ in 2018 , outcomes evaluation has only been carried out subjectively, clinically ${ }^{[11,12,22,33]}$ or through bidimensional photographs ${ }^{[15,16,43,48,50,68]}$, sometimes even taken without standardized conditions ${ }^{[13,24,27,28,32,52,69]}$, the Global Aesthetic Assessment Scale as evaluated by both patients and doctors ${ }^{[17,21,43,48,50,66]}$, and 


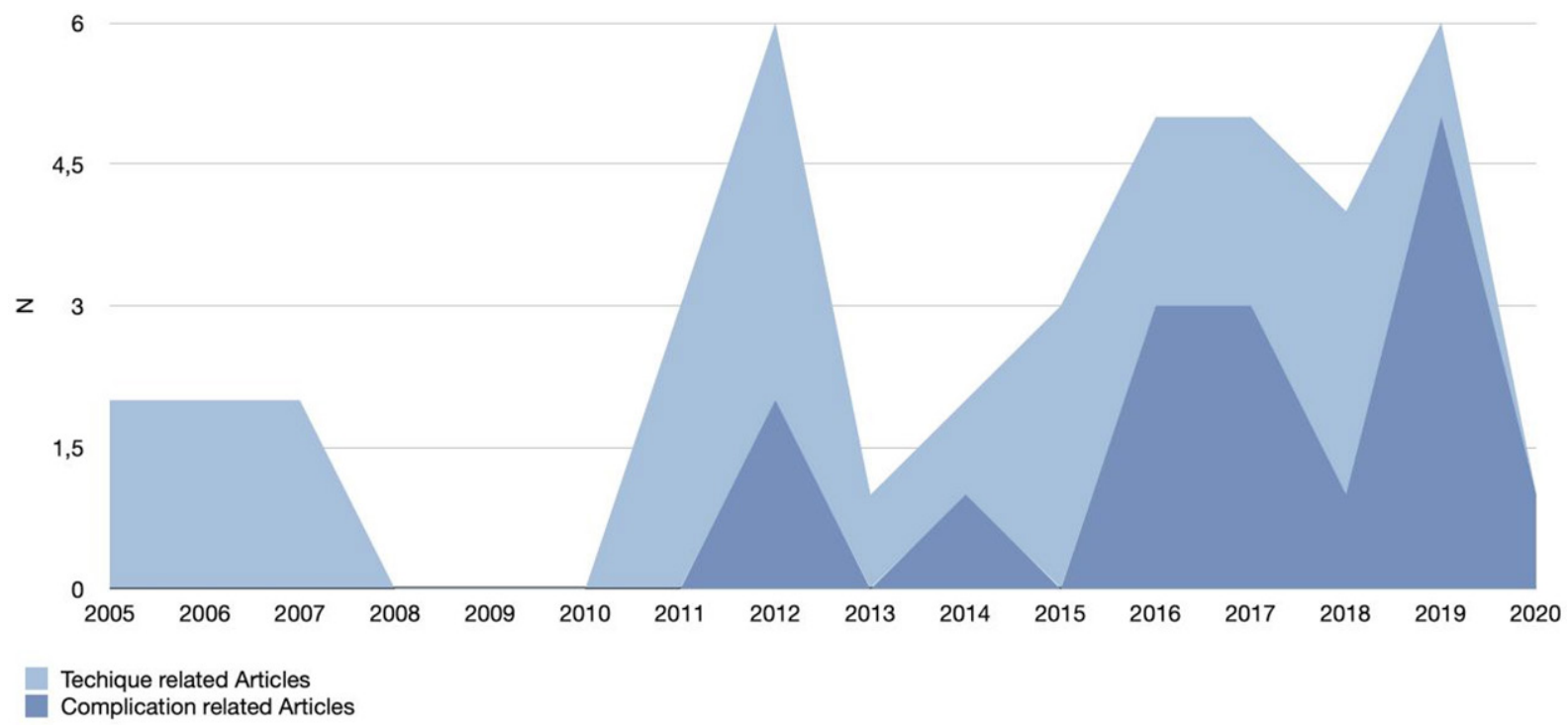

Figure 6. Techniques and complications focused articles: publication trend

administered questionnaires ${ }^{[71]}$, even by telephone calls ${ }^{[26]}$.

It is remarkable that only one paper has focused on instrumental follow-up and outcomes evaluation with ultrasound and this was published in $2013^{[73]}$. No other related research has been carried out since.

Whilst surgical management remains the standard for lower eyelid rejuvenation, non-surgical correction of its selected deformities, such as the tear trough by HA injections may provide a reliable and viable option based upon the presented evidence.

In the author's experience, this treatment can achieve, when properly executed, great satisfaction of both patients and doctors, due to its immediate result and longevity, as it can be assessed for up to 1 year after the injection.

To the best of the authors' knowledge, this is the first literature review related to HA use in lower eyelid for tear trough deformity correction and rejuvenation.

\section{CONCLUSION}

This review has been performed based on the common assumption that when a method to determine the true outcomes, safety and reliability of treatments is lacking besides the mere judgement of patients and clinicians, evidence has to be incorporated into daily clinical practice by considering case reports, pilot studies and available, high-quality studies, as the authors believe that evidence based medicine is essential to provide better answers for both the patients and us healthcare professionals ${ }^{[79]}$.

Further prospective, randomized controlled studies and systematic reviews of the literature are thus desirable, along with a standardized and widely-accepted grading system of the deformity and its treatment outcomes will allow us to better codify this procedure.

\section{DECLARATIONS}




\section{Acknowledgments}

The authors would like to thank Giulia Tanteri, an independent medical writer, who provided Englishlanguage editing and journal styling prior to submission.

\section{Author's contributions}

Made substantial contributions to conception and design of the study, performed data analysis and interpretation: Diaspro A

Verified the analytical methods, provided critical feedback and helped shape the research, analysis and manuscript: Sito G

Contributed to the final manuscript the final manuscript: Diaspro A, Sito G

\section{Availability of data and materials}

Not applicable.

\section{Financial support and sponsorship}

None.

\section{Conflict of interest}

All authors declared that there are no conflicts of interest.

\section{Ethical approval and consent to participate}

Not applicable.

\section{Consent for publication}

Not applicable.

\section{Copyright}

(c) The Author(s) 2020.

\section{REFERENCES}

1. Loeb R. Fat pad sliding and fat grafting for leveling lid depressions. Clin Plast Surg 1981;8:757-76.

2. Flowers RS. Tear trough implants for correction of tear trough deformity. Clin Plast Surg 1993;20:403-15.

3. Hamra ST. Arcus marginalis release and orbital fat preservation in midface rejuvenation. Plast Reconstr Surg 1995;96:354-62.

4. Fante RG, Baker SR. Fat-conserving aesthetic lower blepharoplasty. Ophthalmic Surg Lasers 2001;32:41-7.

5. Huang T. Reduction of lower palpebral bulge by plicating attenuated orbital septa: a technical modification in cosmetic blepharoplasty. Plast Reconstr Surg 2000;105:2552-8; discussion 2559-60.

6. Carraway JH, Coleman S, Kane MA, Patipa M. Periorbital rejuvenation. Aesthet Surg J 2001;21:337-43.

7. Seiff SR. The fat pearl graft in ophthalmic plastic surgery: everyone wants to be a donor! Orbit 2002;21:105-9.

8. Roberts TL 3rd. Laser blepharoplasty and laser resurfacing of the periorbital area. Clin Plast Surg 1998;25:95-108.

9. Lieb WE, Klink T, Münnich S. CO2 and erbium YAG laser in eyelid surgery. A comparison. Ophthalmologe 2000;97:835-41.

10. Lucarelli MJ, Khwarg SI, Lemke BN, Kozel JS, Dortzbach RK. The anatomy of midfacial ptosis. Ophthalmic Plast Reconstr Surg 2000;16:7-22.

11. Airan LE, Born TM. Nonsurgical lower eyelid lift. Plast Reconstr Surg 2005;116:1785-92.

12. Kane MA. Treatment of tear trough deformity and lower lid bowing with injectable hyaluronic acid. Aesthetic Plast Surg 2005;29:363-7.

13. Steinsapir KD, Steinsapir SM. Deep-fill hyaluronic acid for the temporary treatment of the naso-jugal groove: a report of 303 consecutive treatments. Ophthalmic Plast Reconstr Surg 2006;22:344-8.

14. Donath AS, Glasgold RA, Meier J, Glasgold MJ. Quantitative evaluation of volume augmentation in the tear trough with a hyaluronic acid-based filler: a three-dimensional analysis. Plast Reconstr Surg 2010;125:1515-22.

15. Viana GA, Osaki MH, Cariello AJ, Damasceno RW. Treatment of tear trough deformity with hyaluronic acid gel filler. Arq Bras Oftalmol 2011;74:44-7.

16. Viana GA, Osaki MH, Cariello AJ, Damasceno RW, Osaki TH. Treatment of the tear trough deformity with hyaluronic acid. Aesthet Surg $J$ 2011;31:225-31.

17. Berguiga M, Galatoire $\mathrm{O}$. Tear trough rejuvenation: a safety evaluation of the treatment by a semi-cross-linked hyaluronic acid filler. 
Orbit 2017;36:22-6.

18. Mitchell DA, Lyons AB, Moy RL. Correction of cicatricial and involutional lower eyelid ectropion with hyaluronic acid. JAAD Case Rep 2018;4:628-30.

19. Innocenti A, Melita D, Ghezzi S, Innocenti M. Refinements in tear trough deformity correction: intraoral release of tear trough ligaments: anatomical consideration and clinical approach. Aesthetic Plast Surg 2018;42:1576-81.

20. Vasquez RAS, Park K, Braunlich K, Aguilera SB. Prolonged periorbicular edema after injection of hyaluronic acid for nasojugal groove correction. J Clin Aesthet Dermatol 2019;12:32-5.

21. Hussain SN, Mangal S, Goodman GJ. The tick technique: a method to simplify and quantify treatment of the tear trough region. $J$ Cosmet Dermatol 2019;18:1642-7.

22. Goldberg RA, Fiaschetti D. Filling the periorbital hollows with hyaluronic acid gel: initial experience with 244 injections. Ophthalmic Plast Reconstr Surg 2006;22:335-41; discussion 341-3.

23. Goldberg RA, Lee S, Jayasundera T, et al. Treatment of lower eyelid retraction by expansion of the lower eyelid with hyaluronic Acid gel. Ophthalmic Plast Reconstr Surg 2007;23:343-8.

24. Lambros VS. Hyaluronic acid injections for correction of the tear trough deformity. Plast Reconstr Surg 2007;120:74S-80.

25. Kashkouli MB, Heirati A, Pakdel F, Kiavash V. Diplopia after hyaluronic acid gel injection for correction of facial tear trough deformity. Orbit 2012;31:330-1.

26. Hamman MS, Goldman MP, Fabi SG. Comparison of two techniques using hyaluronic acid to correct the tear trough deformity. $J$ Drugs Dermatol 2012;11:e80-4.

27. Wollina U. Improvement of tear trough by monophasic hyaluronic acid and calcium hydroxylapatite. J Clin Aesthet Dermatol 2014;7:38-43.

28. Jiang J, Wang X, Chen R, et al. Tear trough deformity: different types of anatomy and treatment options. Postepy Dermatol Alergol 2016;33:303-8.

29. Or L, Eviatar JA, Massry GG, Bernardini FP, Hartstein ME. Xanthelasma-like reaction to filler injection. Ophthalmic Plast Reconstr Surg 2017;33:244-7.

30. Berros P, Armstrong BK, Foti P, Mancini R. Cosmetic adolescent filler: an innovative treatment of the "Selfie" complex. Ophthalmic Plast Reconstr Surg 2018;34:366-8.

31. Bagci B. A new technique for the correction of tear trough deformity via filler injections. Plast Reconstr Surg 2018;6:e1901.

32. Morley AM, Malhotra R. Use of hyaluronic acid filler for tear-trough rejuvenation as an alternative to lower eyelid surgery. Ophthalmic Plast Reconstr Surg 2011;27:69-73.

33. Kane MA. Advanced techniques for using Restylane in the lower eyelids. Aesthet Surg J 2007;27:90-2.

34. Fezza JP. Nonsurgical treatment of cicatricial ectropion with hyaluronic acid filler. Plast Reconstr Surg 2008;121:1009-14.

35. Zamani M, Thyagarajan S, Olver JM. Functional use of hyaluronic acid gel in lower eyelid retraction. Arch Ophthalmol 2008;126:1157-9.

36. Glaser DA, Patel U. Enhancing the eyes: use of minimally invasive techniques for periorbital rejuvenation. $J$ Drugs Dermatol 2010;9:s118-28.

37. Peckinpaugh JL, Reddy HS, Tower RN. Large particle hyaluronic acid gel for the treatment of lower eyelid retraction associated with radiation-induced lipoatrophy. Ophthalmic Plast Reconstr Surg 2010;26:377-9.

38. Stutman RL, Codner MA. Tear trough deformity: review of anatomy and treatment options. Aesthet Surg J 2012;32:426-40.

39. Dayan SH, Arkins JP, Somenek M. Restylane persisting in lower eyelids for 5 years. J Cosmet Dermatol 2012;11:237-8.

40. Sharad J. Dermal fillers for the treatment of tear trough deformity: a review of anatomy, treatment techniques, and their outcomes. $J$ Cutan Aesthet Surg 2012;5:229-38.

41. Rzany B, Cartier H, Kestermont P, et al. Correction of tear troughs and periorbital lines with a range of customized hyaluronic acid fillers. J Drugs Dermatol 2012;11:s27-34.

42. Trevidic P. The use of blunt-tipped cannulas for tear trough correction. J Drugs Dermatol 2012;11:s38-40

43. Lim HK, Suh DH, Lee SJ, Shin MK. Rejuvenation effects of hyaluronic acid injection on nasojugal groove: prospective randomized split face clinical controlled study. J Cosmet Laser Ther 2014;16:32-6.

44. Hartstein ME. Injectable adjunctive procedures for cosmesis and function. Facial Plast Surg Clin North Am 2016;24:139-44.

45. Turkmani MG. New classification system for tear trough deformity. Dermatol Surg 2017;43:836-40.

46. Lee S, Yen MT. Nonsurgical rejuvenation of the eyelids with hyaluronic acid gel injections. Semin Plast Surg 2017;31:17-21.

47. Sharad J. Treatment of the tear trough and infraorbital hollow with hyaluronic acid fillers using both needle and cannula. Dermatol Ther 2020;33:e13353.

48. Huber-Vorländer J, Kürten M. Correction of tear trough deformity with a cohesive polydensified matrix hyaluronic acid: a case series. Clin Cosmet Investig Dermatol 2015;8:307-12.

49. El-Garem YF. Estimation of bony orbit depth for optimal selection of the injection technique to correct the tear trough and palpebromalar groove. Dermatol Surg 2015;41:94-101.

50. Hill RH 3rd, Czyz CN, Kandapalli S, et al. Evolving minimally invasive techniques for tear trough enhancement. Ophthalmic Plast Reconstr Surg 2015;31:306-9.

51. Artzi O, Loizides C, Verner I, Landau M. Resistant and recurrent late reaction to hyaluronic acid-based gel. Dermatol Surg 2016;42:31-7.

52. Pascali M, Quarato D, Pagnoni M, Carinci F. Tear trough deformity: study of filling procedures for its correction. J Craniofac Surg 2017;28:2012-5.

53. Teo AA, Mokhtarzadeh A, Cameron JD, Harrison AR. Late presentation of enlarging lower eyelid mass and muscle degeneration 
secondary to hyaluronic acid filler. Ophthalmic Plast Reconstr Surg 2017;33:S9-11.

54. Iverson SM, Patel RM. Dermal filler-associated malar edema: treatment of a persistent adverse effect. Orbit 2017;36:473-5.

55. Parulan MAA, Sundar G, Lum JH, Ramachandran U. A case report on dermal filler-related periorbital granuloma formation. Orbit 2019;38:169-72.

56. Wulu JA, Garcia-Rodriguez L, Prilutskiy A, Spiegel JH. The case of the eyelid silicone granulomas. Am J Otolaryngol 2019;40:776-8.

57. Kalin-Hajdu E, Kersten RC. Nasolacrimal duct obstruction following hyaluronic acid rejuvenation of the tear trough. Ophthalmic Plast Reconstr Surg 2019;35:e14-5.

58. Wong $\mathrm{CH}$, Hsieh MK, Mendelson B. The tear trough ligament: anatomical basis for the tear trough deformity. Plast Reconstr Surg 2012;129:1392-402.

59. El Rayes EN, Elborgy E. Suprachoroidal buckling: technique and indications. J Ophthalmic Vis Res 2013;8:393-9.

60. Griepentrog GJ, Lemke BN, Burkat CN, Rose JG Jr, Lucarelli MJ. Anatomical position of hyaluronic acid gel following injection to the infraorbital hollows. Ophthalmic Plast Reconstr Surg 2013;29:35-9.

61. Surek C, Beut J, Stephens R, Lamb J, Jelks G. Volumizing viaducts of the midface: defining the Beut techniques. Aesthet Surg $J$ 2015;35:121-34.

62. Peng PH, Peng JH. Treating the tear trough: a new classification system, a 6-step evaluation procedure, hyaluronic acid injection algorithm, and treatment sequences. J Cosmet Dermatol 2018;17:333-9.

63. Zoumalan CI. Managing periocular filler-related syndrome prior to lower blepharoplasty. Aesthetic Plast Surg 2019;43:115-22.

64. Tung R, Ruiz de Luzuriaga AM, Park K, et al. Brighter eyes: combined upper cheek and tear trough augmentation: a systematic approach utilizing two complementary hyaluronic acid fillers. J Drugs Dermatol 2012;11:1094-7.

65. El Rayes EN. Suprachoroidal buckling. In: Oh H, Oshima Y, editors. Microincision Vitrectomy Surgery. Basel: S. KARGER AG; 2014. pp. 135-46.

66. Worley B, Huang JW, Macdonald J. Approach to treatment of cicatricial ectropion: a systematic review and meta-analysis comparing surgical and minimally invasive options. Arch Dermatol Res 2020;312:165-72.

67. Xi W, Han S, Feng S, et al. The Injection for the lower eyelid retraction: a mechanical analysis of the lifting effect of the hyaluronic acid. Aesthetic Plast Surg 2019;43:1310-7.

68. Hilton S, Schrumpf H, Buhren BA, Bölke E, Gerber PA. Hyaluronidase injection for the treatment of eyelid edema: a retrospective analysis of 20 patients. Eur J Med Res 2014;19:30.

69. Choi SY, Ko EJ, Kim BJ, Song KY, Kim WS. Lump on the lower eyelid due to hyaluronic acid filler. Clin Exp Dermatol 2016;41:94-5.

70. Skippen B, Baldelli I, Hartstein M, et al. Rehabilitation of the dysmorphic lower eyelid from hyaluronic acid filler: what to do after a good periocular treatment goes bad. Aesthet Surg J 2020;40:197-205.

71. Hall MB, Roy S, Buckingham ED. Novel use of a volumizing hyaluronic acid filler for treatment of infraorbital hollows. JAMA Facial Plast Surg 2018;20:367-72.

72. Mustak H, Fiaschetti D, Goldberg RA. Filling the periorbital hollows with hyaluronic acid gel: Long-term review of outcomes and complications. J Cosmet Dermatol 2018;17:611-6.

73. De Pasquale A, Russa G, Pulvirenti M, Di Rosa L. Hyaluronic acid filler injections for tear-trough deformity: injection technique and high-frequency ultrasound follow-up evaluation. Aesthetic Plast Surg 2013;37:587-91.

74. Cho SY, Park JW, An H, et al. Physical properties of a novel small-particle hyaluronic acid filler: In vitro, in vivo, and clinical studies. $J$ Cosmet Dermatol 2018;17:347-54.

75. Romero R, Sanchez-Orgaz M, Granados M, et al. Use of hyaluronic acid gel in the management of cicatricial ectropion: results and complications. Orbit 2013;32:362-5.

76. Meier JD, Glasgold RA, Glasgold MJ. 3D photography in the objective analysis of volume augmentation including fat augmentation and dermal fillers. Facial Plast Surg Clin North Am 2011;19:725-35, ix.

77. Calvisi L, Diaspro A, Sito G. Tear trough. In: Acta Medica Griffin, editors. Fillers - Illustrated Manual of Injection Techniques. Cantù: Griffin Editore; 2020. pp. 37-54.

78. CEBM News Release. Oxford Centre for Evidence-Based Medicine. Available from: https://www.cebm.net/index.aspx?o=5653. [Last accessed on 19 Oct 2020]

79. Eaves F 3rd, Pusic AL. Why evidence-based medicine matters to aesthetic surgery. Aesthet Surg J 2012;32:117-9. 